\title{
Institutional Care for the Mentally Defective, 1914- 1948: Diversity as a Response to Individual Needs and an Indication of Lack of Policy Coherence
}

\author{
GRAHAM CHESTER and PAMELA DALE*
}

In recent years mental deficiency policy and the wider issue of the history of people with learning difficulties have attracted much attention. Important publications by Mathew Thomson, Anne Digby, Mark Jackson, David Wright and others have led to a reassessment of mental deficiency provision. ${ }^{1}$ These scholars have firmly placed mental deficiency services within a mixed economy of care, with statutory and voluntary sector organizations providing institutional and community-based services in cooperation, and also in competition, with one another. The politics of service-delivery provided an important strand of analysis in Thomson's The problem of mental deficiency, but he did not seek to investigate any one institution, preferring instead to concentrate on the wider debates that informed service-development. ${ }^{2}$ This enabled him to link changes in the sector to much wider social, economic, political and intellectual trends in ways that have stimulated a great deal of interest and research. To date most attention has concentrated on case studies of specialist institutions before 1914 and the development of community care in the twentieth century. This leaves something of a gap in the literature because institutions (created before and after 1914) are relatively neglected in studies of the implementation of the 1913 and 1927 Mental Deficiency Acts. The place of such institutions within the mixed economy of care therefore remains uncertain.

This paper places institutions at the core of provision after 1914 and suggests diversity in schemes of institutional and community care as a new way of understanding the relationship between the two. Within the mixed economy of care there were groups identifiable as "purchasers" and "providers" of care, if we borrow twenty-first-century terminology. The key purchasers of care were the local authorities with statutory responsibilities for mental

CGraham Chester and Pamela Dale 2007

*Graham Chester, BA (hons), an Arts and Humanities Research Council funded PhD student, and Pamela Dale, PhD, Wellcome Research Fellow, are based in the Centre for Medical History, Amory Building, Rennes Drive, University of Exeter, Exeter, Devon, EX4 4RJ, UK.

The authors would like to thank the editors and referees of Medical History for their generous assistance, and Pamela Dale would like to acknowledge the support received from the Arts and Humanities Research Board (now the Arts and Humanities Research Council) and the Exeter University Foundation for her $\mathrm{PhD}$ research that this article draws upon.

${ }^{1}$ Mathew Thomson, The problem of mental deficiency: eugenics, democracy and social policy in
Britain c. 1870-1959, Oxford, Clarendon Press, 1998; David Wright and Anne Digby (eds), From idiocy to mental deficiency: historical perspectives on people with learning disabilities, London, Routledge, 1996; Mark Jackson, The borderland of imbecility: medicine, society and the fabrication of the feeble mind in late Victorian and Edwardian England, University of Manchester Press, 2000; Peregrine Horden and Richard Smith (eds), The locus of care: families, communities, institutions and the provision of welfare since Antiquity, London, Routledge, 1998; Peter Bartlett and David Wright (eds), Outside the walls of the asylum: the history of care in the community 1750-2000, London, Athlone Press, 1999; David Wright, Mental disability in Victorian England: the Earlswood Asylum, 1847-1901, Oxford, Clarendon Press, 2001.

${ }^{2}$ Thomson, op. cit., note 1 above, pp. 3-4. 


\section{Graham Chester and Pamela Dale}

deficiency work. Identifying the providers of care is more difficult, because they were more numerous and subject to change over time. The 1913 Mental Deficiency Act (MDA) recognized that a number of specialist facilities as well as general institutions (including prisons and workhouses) already provided accommodation for people classified as "defectives" within the meaning of the act. For commentators like David Garland, ${ }^{3}$ this firmly locates mental deficiency services within an increasingly elaborate penal-welfare system. Yet, in the Edwardian period, institutional care for the mentally defective was advocated by individuals concerned to improve the care of, as well as control over, people who later became subject to the provisions of the MDA. This meant that the broad ideological consensus, which is apparent from Thomson's work, was able to support the MDA, despite continuing debate about the most appropriate balance of care and control. $^{4}$

Campaigners who supported the legislation were, however, concerned that the accommodation provided before the MDA was inadequate. On one level it was insufficient for the number of "defectives" they expected to identify and bring under the control of the act, but there was also concern that the care regimes offered by many of these pre-existing institutions were inappropriate. This led to attempts to curtail the use of unsuitable general institutions (especially prisons and workhouses), adapt the regimes of existing specialist institutions to bring them into conformity with the new agenda for care heralded by the 1913 act, and create new institutions (controlled by local authorities and run on "colony" lines) to enable the full implementation of the legislation.

Supporters of the 1913 MDA tended to view mental deficiency as a national problem but the implementation of this legislation was a task for local government, overseen by a newly created Board of Control. Different local authorities responded in a variety of ways, their actions often being conditional on a range of factors that to date have been unexplored beyond general statements about unequal amounts of financial resources and political will. This paper considers the three different schemes for mental deficiency work developed by the Somerset, Devon, and Dorset county councils. These three local authorities have been chosen because they shared a partnership agreement with the managing committee of the Royal Western Counties Institution (RWCI) at Starcross in Devon (a former voluntary idiot asylum established in the 1860s and a major provider of institutional accommodation after 1914). They also shared a good deal of data with each other and often conducted joint negotiations with the Board of Control. All three made repeated commitments to developing a comprehensive mental deficiency service, and expressed continuing support for institutional segregation.

These important similarities did not, however, result in a common strategy for mental deficiency work. A combination of local preferences and local circumstances dictated different approaches to the problem of creating a mental deficiency service. It will be shown that Somerset benefited to an unusual extent from a very active voluntary sector that had been interested in the problem for many years before 1914 (and this included links to the voluntary asylum at Starcross). Somerset pioneered a scheme based on a cluster of

\footnotetext{
${ }^{3}$ David Garland, Punishment and welfare: a history of penal strategies, Aldershot, Gower, 1985.

${ }^{4}$ Thomson, op. cit., note 1 above, introduction.
} 


\section{Institutional Care for the Mentally Defective, 1914-1948}

institutions closely integrated with each other and community-based services. Devon and Dorset had fewer resources to draw on but at an early stage adopted two different approaches. The statutory authority in Devon was determined to be a provider of institutional care as well as a purchaser of services. The goal of a county asylum dominated longterm planning in Devon, although in the short term the county council acceded to Board of Control requests to work in cooperation with the RWCI. Dorset was equally determined not to become a direct provider of mental deficiency services and instead supported eugenic policies to limit future numbers while utilizing workhouse beds and specialist out-ofcounty placements. In a limited way this included the RWCI.

Institutional care (though not necessarily the RWCI) was at the heart of all these local authority schemes for mental deficiency work. Beds in institutions were, however, relatively scarce and expensive because the development of new institutions was severely hampered by financial and organizational difficulties. Elsewhere Pamela Dale has argued that the slow development of new institutions had a long-term impact on the development of both institutional and community care. ${ }^{5}$ This occurred not least because pre-existing institutions exerted a strong influence over service development that had not been anticipated by campaigners who had pressed for the legislation. The cost and shortage of beds also arguably led to a situation where community care was developed as an adjunct, rather than real alternative, to institutional care.

Institutions were vital to the implementation of the Mental Deficiency Acts. They provided a distinct locus of care and supported arrangements for extra-institutional care. Mark Jackson and others have gone further by arguing that institutions operated as a site where the meanings of normality and deficiency were constructed. ${ }^{6}$ This is undoubtedly true, although it could be argued that the diversity of institutional provision discussed in this paper allowed the construction of alternative and competing definitions. This led to a situation where diversity in provision was both a response to individual needs and an indication of lack of policy coherence.

\section{A Preference for Institutional Care?}

In Somerset, Mrs Norah Cooke-Hurle (née Fry), ${ }^{7}$ the long-serving chair of the statutory mental deficiency committee and a key member of the Somerset Association for Mental Welfare (SAMW), provided a vital link between the statutory and voluntary sectors. She used her powerful position within the local authority to secure the cooperation of other councillors, and officers, while deploying the resources of the voluntary sector to good effect. Voluntary organizations with an interest in mental deficiency work had existed in Somerset for many years before the MDA but after 1914 the most important was the newly formed Somerset Association for the Care of the Mentally Defective, renamed the SAMW

\footnotetext{
${ }^{5}$ Pamela Dale, 'Implementing the 1913 Mental Deficiency Act: competing priorities and resource constraint evident in the South West of England before 1948', Soc. Hist. Med., 2003, 16: 403-18.

${ }^{6}$ Jackson, op. cit., note 1 above.

${ }^{7} \mathrm{We}$ are indebted to Oliver Russell, the former Honorary Director of the Norah Fry Research Centre:
}

Research on Services for People with Learning Difficulties at the University of Bristol, for facilitating access to his personal collection of papers relating to the life of Norah Fry (1871-1960). These included a copy of the obituary written by Sir Philip Morris that appeared in The Times, 17 June 1960, p. 19. 


\section{Graham Chester and Pamela Dale}

in 1921. This organization raised funds from wealthy supporters to acquire mental deficiency institutions, which were later taken over by Somerset County Council. ${ }^{8}$ In the 1920 s and 1930s Somerset County Council operated four institutions. Yatton Hall (for severely disabled children) and Sandhill Park (for trainable children) had been established by the voluntary sector, with generous patrons encouraging more ambitious schemes than might otherwise have been contemplated by the statutory authority. The other two institutions, known as Cambridge House and West End House, were parts of the Long Ashton and Shepton Mallet workhouses. This accommodation had been certified for mental deficiency cases by the Board of Control in 1917 and 1919. These two workhouses were finally appropriated by the county council after the 1929 Local Government Act, but local interest in dedicated institutional provision for the mentally defective meant that these institutions had already provided specialist beds for almost thirty years. ${ }^{9}$

After 1914 Mrs Cooke-Hurle was able to coordinate mental deficiency services, previously developed by the voluntary sector and Boards of Guardians, through her extensive personal contacts and political connections. She also managed to work in cooperation with a number of the council's own departments without having to concede leadership of the service to interested professionals. The Somerset Medical Officer of Health was rarely prominent in debates about mental deficiency; rather Mrs Cooke-Hurle developed a number of local, regional and national platforms to disseminate her views on the subject. ${ }^{10}$ She supported the idea that different services might meet different needs and endorsed lay education and training programmes within the context of a Board of Control approved medical model of care. ${ }^{11}$

Mrs Cooke-Hurle drew on a local model of care that predated the 1913 MDA and it was this comprehensive network of pre-existing services that was expanded and developed after 1914. The Board of Control praised Somerset as a good provider of institutional care, and the high rate of ascertainment (the process of identifying and bringing "defectives" under the control of the MDAs) suggests community services were also well developed. Jan Walmsley and her colleagues strongly suggest that it was this early provision that later encouraged Somerset to develop measures that characterized it as an "interventionist local authority". ${ }^{12}$ After 1914, and more significantly after the disruptions associated with the First World War, the numbers of people assessed as potential "defectives" and made subject to the provisions of the 1913 MDA certainly increased. These certified mental

\footnotetext{
${ }^{8}$ The evolution of statutory and voluntary services in Somerset is summarized by Eric Rose, Services for people with a mental handicap: a brief history of the development of hospital care in the county of Somerset Taunton, Somerset County Council Social Services Department, 1989.

${ }^{9}$ Ibid., pp. 9-10.

${ }^{10}$ The role of the County Medical Officer of Health has attracted far less interest and research than his municipal medical colleagues, although it might be anticipated that the greater geographical area served necessitated less personal involvement with particular problems and schemes to alleviate them. Professional and personal interests may have been important, as the Devon Medical Officer of Health took a leading role in mental deficiency work.
}

\footnotetext{
${ }^{11}$ Mrs Cooke-Hurle was closely associated with both institutional and community services, such as the occupation centres, initiated by the SAMW, and also sat as the Somerset County Council representative on the managing committee of the RWCI. She supported the appointment of a resident medical officer at the RWCI and widely canvassed support for her preferred candidate. Exeter University Library RWCI Collection (hereafter RWCI Collection), Joint Committee of RWCI, special sub-committee, 18 Jan. 1938, minute 28 .

${ }^{12}$ Jan Walmsley, Dorothy Atkinson, and Sheena Rolph, 'Community care and mental deficiency 1913 to 1945', in Bartlett and Wright (eds), op. cit., note 1 above, pp. 181-203, p. 189.
} 


\section{Institutional Care for the Mentally Defective, 1914-1948}

deficiency cases were eligible for admission to institutions or a variety of communitybased care services. In Somerset, beds in institutions remained scarce and expensive, but it is arguable that institutional care remained central to the council's mental deficiency plans. Throughout the period the local authority funded the expansion of existing and new institutions. It also appears that new services based in the community were designed to support the work of these institutions.

The important point is made by Walmsley and her colleagues that in Somerset community care operated "alongside institutional care, not in opposition to it", but arguably more emphasis needs to be placed on the centrality of institutional care within a model of service delivery that had institutional and community care elements. ${ }^{13}$ Community care was framed by the need to monitor and support individuals and families while an assessment for institutional care was made. It was also designed to provide services for individuals waiting for institutional care, people not in immediate need of institutional care, and those patients normally resident in institutions but temporarily at home on holiday or extended licence. These groups included people who would never actually be admitted to institutions but whose continuing care was assessed on the basis that they might need to be institutionalized at some point in the future.

In contrast to today, institutional care was often the preferred solution rather than the destination of last resort, and there is little evidence to suggest that the expansion of community services challenged these attitudes within the statutory authority. Instead community care was often about expanding the reach of the institution into the community. It is also possible that the expansion of community services was viewed as a temporary measure pending the completion of planned but undelivered institutional schemes. For example, developments at the RWCI were intended to create more than 200 Somerset beds in the first phase alone. Preliminary works started in 1929 but construction was delayed until the eve of the Second World War and then the new facilities were allocated to evacuees. ${ }^{14}$ The council experienced similar problems with its own Sandhill Park Colony, even before the army requisitioned it in $1940 .^{15}$

With institutions, in theory if not in practice, dominating local provision, the community care offered had a strong element of community surveillance as well as service delivery. The behaviour of individuals and the quality of home care provided by their relatives was closely scrutinized. These surveillance activities were not incompatible with support for parents, but whether care or control were the dominant themes of the work the result was much the same. People were institutionalized to reduce the burden of care on respectable families, to receive better care/treatment than they could at home, and to punish disreputable and/or uncooperative families. Thus the application for institutional care for "Donald" noted that continuing home care presented a risk to the development of his siblings and suggested, "the mother's health will suffer if she has to look after him much

\footnotetext{
${ }^{13}$ Ibid., p. 196.

${ }^{14}$ RWCI Collection, Joint Committee of RWCI, special sub-committee, 27 July 1940, discussed and declined proposals to create an army psycho-neurotic unit at the Langdon Colony. Instead it agreed to take up to 200 cases evacuated from Sandhill Park. These were
}

Somerset cases, but they were not the patients the beds had been intended for.

${ }^{15}$ The military use of this facility is briefly described in Edgar Jones, 'War and the practice of psychotherapy: the UK experience 1939-1960', Med. Hist., 2004, 48: 493-510, pp. 495-6. 


\section{Graham Chester and Pamela Dale}

longer". ${ }^{16} \mathrm{Mr} \mathrm{C}$, whose home circumstances were described as "particularly good", also requested an institutional place for his son on the grounds that "my son's mental condition will not improve without the special training I am unable to give him". ${ }^{17}$ The home report on "Betty" was regarded as "unsatisfactory" and an institutional place was sought. No mention was made of the parents' views and it is possible they were disregarded because of the allegation that "the child is very dirty and neglected". ${ }^{18}$ While all these individuals appear to have been living at home immediately before the application for institutional care, no long-term community solution to their problems appears to have been considered. Hence the permanently long waiting lists and demands for ever-more institutional beds.

While local authorities such as Somerset had developed community services to facilitate their ascertainment work, very little thought appears to have been given to aftercare, and this concentration on pre-admission services was even more noticeable in areas where extra-institutional services were established at a later date. ${ }^{19}$ This further reinforces the idea that, in theory at least, permanent care was seen as both desirable and possible. Providers of institutional care, such as the RWCI, argued strongly that this was not the case, and tried to make future admissions dependent upon other patients leaving the institution. This was understood by the partner local authorities, but only in the narrow sense that they could create vacancies for urgent cases by requesting transfers for other patients and could specify which patient on the waiting list would replace a patient who had died. Thus Somerset County Council requested that "the vacancies caused by the death of these patients can be filled by the admission of Kenneth S . ., and Alice K". ${ }^{20}$ In other cases the council clerk proposed elaborate swaps involving transfers not only between institutions but also between categories of patients to secure urgently needed accommodation. In one example he argued that "Barbara" had advanced to such an extent at Yatton Hall (a small home for severely disabled children) that she could be considered "an imbecile of higher grade and suitable to mix with lower grade feeble-minded patients". ${ }^{21}$ If the RWCI would accept her, the urgent cases (that the RWCI would have been determined to refuse because they were "low grade" and expensive to nurse) would go to Yatton Hall. The superintendent agreed to this. ${ }^{22}$

The interwar period in Somerset witnessed the creation of new institutions, the reconfiguration of existing ones to make them more suitable for mental deficiency work, and a commitment to the provision of residential special education followed by institutional training for children. This was not incompatible with innovations in community care but the institutions consumed so many resources that community services were in danger of

\footnotetext{
${ }^{16}$ RWCI Collection, file marked Somerset Mental Deficiency Committee, Jan. 1939 to Dec. 1940, letter from H King (Clerk) and C W Mayer (RWCI superintendent), 21 Apr. 1939.

${ }^{17}$ RWCI Collection, file marked Somerset Mental Deficiency Committee, Jan. 1939 to Dec. 1940, correspondence between H King and C W Mayer, 7 Jan. 1939 and 20 Feb. 1939 enclosing letter from Mr C.

${ }^{18}$ RWCI Collection, file marked Somerset Mental Deficiency Committee, Jan. 1939 to Dec. 1940, letter from H King to C W Mayer, 17 Apr. 1939.

${ }^{19}$ In Devon the RWCI had to make independent arrangements with the Devon equivalent of the SAMW
}

to supervise patients temporarily absent from the institution.

${ }^{20}$ RWCI Collection, file marked Somerset Mental Deficiency Committee, Jan. 1939 to Dec. 1940, letter from H King to C W Mayer, 14 Feb. 1939.

${ }^{21}$ RWCI Collection, file marked Somerset Mental Deficiency Committee, Jan. 1939 to Dec. 1940, letter from H King to C W Mayer, 13 Apr. 1939.

${ }^{22}$ RWCI Collection, file marked Somerset Mental Deficiency Committee, Jan. 1939 to Dec. 1940, letter dated 28 Apr. 1939. 


\section{Institutional Care for the Mentally Defective, 1914-1948}

being neglected by the statutory authority. Community care services were therefore heavily dependent on the voluntary sector for staff and funds. ${ }^{23}$ In January 1939, 671 cases that had come to the attention of the SAMW were in specialist mental deficiency institutions, with a further 95 children in residential schools, and 24 individuals resident in Public Assistance Institutions; a total of 790. A further 181 patients were on leave from institutions, while 94 individuals were under guardianship, 221 received statutory supervision, and 109 were supported by public assistance in domiciliary settings. These 605 people were also under the care/control of the statutory authorities whereas a further 975, including 193 schoolchildren, were only subject to "friendly supervision" by the voluntary organization. ${ }^{24}$

Where community services prospered in Somerset it was usually as an adjunct rather than an alternative to institutional care. Even where individuals were supported at home for long periods, this was often presented in the light of there being no immediate need for institutional care, rather than the community programme offering a real alternative. It is noticeable that 30 of the patients technically on leave from institutions were actually resident in temporary accommodation, and 20 cases were receiving statutory supervision pending an overdue institutional placement. ${ }^{25} \mathrm{~A}$ voluminous file of correspondence between Somerset County Council and the RWCI includes many requests for the admission of patients and their transfer between institutions, but, apart from patients who died, there are virtually no references to patients leaving care, although some were allowed periods of licence in the care of relatives and employers. This is not the entire picture, however. The statutory authority had made clear its own support for a particular model of institutional care, but the voluntary sector, as providers of institutional and community care, had some autonomy. Community-based services stressed the legitimacy of community care while institutions like the RWCI managed patients according to their own priorities. Both suggested care over the admission of patients and anticipated discharges despite the reluctance of the statutory authority. ${ }^{26}$

\section{Problems Associated with the Provision of Institutional Care}

Somerset was by no means the only local authority to support institutional care for mental deficiency cases but benefited to an unusual extent from its pre-1914 facilities and particularly close cooperation with a very active voluntary organization. Other local authorities, starting almost from scratch, fared poorly in comparison, especially where they were unable or unwilling to cooperate with other service providers. The RWCI was situated in Devon but, despite its convenient location, was not central to the county council's plans in 1914. This was because the local authority had already tried and failed

\footnotetext{
${ }^{23}$ It is worth noting that the correspondence between Somerset County Council and the RWCI, referred to earlier in this paper, which endorsed institutional placements for people previously living in the community, was dated 1939 , when the local community services were both extensive and long-established.

${ }^{24}$ RWCI Collection, file marked Somerset Mental Deficiency Committee, Jan. 1939 to Dec. 1940, copy of 25th annual report of the Somerset Association for
}

Mental Welfare, 1939. Statistical summary produced by authors from figures given in sections $2-5$. ${ }^{25}$ Ibid

${ }^{26}$ The 25th annual report of the Somerset Association for Mental Welfare, section 4, mentions 15 cases discharged from order by the Board of Control after two years of continuous licence and 15 similar cases discharged by different visiting committees and superintendents. A further 9 cases were transferred to guardianship schemes. 


\section{Graham Chester and Pamela Dale}

to integrate the asylum into its plans for special education following the 1899 Education (Defective and Epileptic Children) Act. The statutory authority in Devon was therefore determined to pursue plans for a comprehensive and independent mental deficiency service elsewhere. ${ }^{27}$ The decision was reaffirmed on several occasions, especially during a review of accommodation in 1919/20, despite the fact that Devon lacked the essential infrastructure that Somerset had developed before and during the First World War. ${ }^{28}$ This took time to establish and, while the 1920s witnessed good progress on increasing ascertainment rates, in Devon institutional provision failed to keep pace, with significant shortages of accommodation reported in the 1920s, 1930s and 1940s. ${ }^{29}$

The statutory authority in Devon was thus left dependent on a number of care providers, which frustrated plans for a unified service. To secure much-needed beds, the council had to accept care regimes that did not match their oft-stated aspirations for mental deficiency work. The council continued to rely heavily on the beds available at Starcross, but relations with the RWCI managing committee were strained by policy differences. The RWCI continued to discharge patients and refused to support overtly eugenic measures. Devon County Council and its "partner" institution thus gave conflicting evidence to the Brock Committee on voluntary sterilization in $1933 .{ }^{30}$ The only local alternative to the RWCI was the use of small homes run by charities. This was costly, hard to supervise, and in many cases introduced an unwelcome religious dimension to placements. Councillors and officials tended to be most concerned about cost, but social workers keen to win the trust of family members had to propose placements that accorded with parents' religious beliefs. It was possible to approach distant institutions run by secular public authorities but negotiating access to beds was a frustrating and time-consuming process that involved assessments of individual patient needs both before and after specific contractual issues were resolved. This was also a problem with admissions to the RWCI, and remained unresolved by successive "partnership" agreements. ${ }^{31}$ Local authorities such as Devon

\footnotetext{
${ }^{27}$ The development of the RWCI before 1914 is discussed by David Gladstone, 'The changing dynamic of institutional care: the Western Counties Idiot Asylum, 1864-1914', in Wright and Digby (eds), op. cit., note 1 above, pp. 134-60.

${ }^{28}$ Somerset had experimented with institutional and community care for the mentally defective at an early date and these services were viewed as suitable for purpose after 1913. In fact many facilities remained in use throughout the inter-war period, and some were maintained until the final closure programme in the 1980s.

${ }^{29}$ Devon Record Office (hereafter DRO), 150/5/1/ 2. Devon Mental Deficiency Committee (hereafter Devon MD Com), minutes of meeting with representatives of the RWCI, 23 Apr. 1936, pp. 1-4. Statistics shared at this meeting confirmed that Devon cases occupied 249 of the 730 beds then available at the RWCI. This was 99 more than the RWCI was contracted to provide and the RWCI expected to lose more than 100 beds as temporary accommodation was phased out. Thus, while a further 200 beds were allocated to Devon as part of the Langdon Colony extension, many of these were replacement beds not
}

new ones. This did nothing to solve the problem of accommodating the Devon cases that needed transferring from Devon Mental Hospital or local Poor Law Institutions, or a number of children who needed admitting from poor homes. Devon Medical Department reported that these cases numbered at least 326.

${ }^{30}$ DRO 150/5/1/2, Devon MD Com, 18 May 1933, minute 767. John P Radford and Allison Tipper, Starcross: out of the mainstream, Toronto, G Allen Roeher Institute, 1988, p. 67, summarize the RWCI position. For full details regarding the Report of the departmental committee on sterilisation, (Brock Report), PP Cmnd. 4485, XV, 1934, see Thomson, op. cit., note 1 above, pp. 193-4, 197-8.

${ }^{31}$ Many local authorities estimated their likely patient population and negotiated the admission of a number of anonymous patients of different grades to the RWCI but a patient could only be admitted to graded accommodation if he or she, personally, presented no complicating factor. This meant that despite broad agreement on the nature of cases to be admitted, a number of other factors were taken into account when the beds were actually allocated. 


\section{Institutional Care for the Mentally Defective, 1914-1948}

that did not have their own accommodation suffered as mental deficiency services elsewhere re-orientated themselves to specific geographical catchment areas, which shrank as overall demand for accommodation increased. ${ }^{32}$

It was not until the 1930s that a new strategy for mental deficiency work emerged in Devon. This was orchestrated by the County Medical Officer of Health and his department and was associated with strong support for eugenic segregation and sterilization policies. ${ }^{33}$ The 1929 Local Government Act gave the local authority its own accommodation for the first time. ${ }^{34}$ The appropriation of former workhouses for mental deficiency work provided much-needed beds and this new competition forced concessions from other care providers. In more confident mood, Devon County Council sought to re-negotiate its partnership with the RWCI and enforce an agenda for change, with the intention of basing a unified mental deficiency service on this site and wresting control of the institution from the independent managing committee. ${ }^{35}$ The slow pace of development at Starcross, interrupted first by the Depression and then the outbreak of war, still left the county reliant on a variety of institutions, few under its direct control. This was viewed as an unsatisfactory alternative to one single county asylum.

In Dorset there is no lack of evidence of strong support for eugenically-inspired segregation and sterilization programmes, but there is little sign of enthusiasm for a single county asylum, such as Devon planned. There was also limited support for a scheme based on a cluster of institutions closely integrated with each other and community-based services, such as Somerset had pioneered. Instead Dorset had a three-pronged strategy: support for measures to limit future numbers, the use of workhouses for adult patients, and the development of out-of-county placements for people needing specialist care. In the short term this was very cost-effective but in the longer term Dorset suffered from the lack of accommodation under direct local authority control and came under pressure from the Board of Control to improve its arrangements.

These difficulties may be linked to the sterilization debate. The RWCI superintendent, $\mathrm{C}$ W Mayer, was concerned that advocates of sterilization apparently regarded the policy as an alternative to segregation and feared that they were postponing investment in institutional care in the forlorn hope that numbers would decline. He used his annual report for $1930 / 31$ to argue strongly that "it is indisputable that the basis of our present-day programme must be institutional". ${ }^{36}$ To a certain extent the Dorset Mental Deficiency Act

\footnotetext{
${ }^{32}$ A number of cases from Devon, Somerset, and Dorset had been admitted to Metropolitan Asylum Board institutions before 1913 and the Board of Control was very keen to secure their removal to local institutions.

${ }^{33}$ Devon County Council regularly debated and endorsed sterilization schemes. DRO 153/5/1/1, Devon MD Com, 22 Nov.1917, minute 113d. References become more frequent after 1925 . See, for example, DRO 153/5/1/1, minutes 449 (16 Feb. 1926), 514 (19 May 1927), and 522 (8 Sept. 1927); and DRO, 153/5/1/ 2, minutes 651 (11 Sept. 1930), 724 (8 Sept. 1932), 740 (10 Nov. 1932), 751 (9 Feb. 1933), and 767 (18 May 1933).

${ }^{34}$ Previously the council owned only a small residential unit for boys.
}

\footnotetext{
${ }^{35}$ This was done by placing Devon County Council representatives on the managing committee. DRO 153/ 5/1/1, Devon MD Com, 11 May 1920, minute 215, agreed to nominate one representative from the education committee and one from the mental deficiency committee. This later increased to a total of five after the joint committee structure was adopted in 1937, RWCI Collection, RWCI Joint Committee 30 Nov. 1937, minutes list those present and the organizations they represented.

${ }^{36}$ RWCI Collection, box 31, Report of the superintendent to the president of the Western Counties Institution, Starcross, for the year ending 31st March 1931, p. 1 .
} 


\section{Graham Chester and Pamela Dale}

(MDA) Committee accepted this position although this did not automatically imply support for the RWCI. Instead, Dorset County Council maintained patients in a wide variety of institutions scattered over England and Wales. They were very keen to publicize this, and circulated statistics about these placements. The motivation for doing so appears to have been to put pressure on service providers to allocate more accommodation to Dorset cases and reduce the costs of such beds, by reminding them of the competition they faced. ${ }^{37}$ Yet, circulated amongst the Dorset statutory committee members, these lists had different, or at least supplementary, meanings. Detailed descriptions of the institutions were provided to show how they were or were not suitable for existing and/or additional cases. Here, there is evidence of an attempt to respond to individual patient circumstances but also hints of confused policy decisions based on incompatible goals.

\section{Institutional Care in a Variety of Settings}

Considerable light is shed on the variety of institutional placements available by a survey of all institutional accommodation provided for Dorset cases undertaken in 1926 by Sir Reginald Pinney, a member of the Dorset MDA Committee and a visitor of certified institutions. ${ }^{38}$ This document also gives an important contemporary assessment of their relative merits.The report is organized chronologically and describes visits to twenty-seven different institutions between June and November 1926. The establishments surveyed provided beds for 106 Dorset patients; 47 males and 59 females (Table 1). The admission criteria of the institutions are not always clear, but it appears that Dorset sent only male patients to five of the asylums. Female cases only were sent to thirteen units, and eight facilities received patients of both sexes. One institution had no Dorset patients, as the single case maintained there had recently died; a note to the effect that care there was "very expensive" suggests that no future placements were contemplated.

There was, however, a variety of accommodation available, and a diversity of provision was sought for Dorset cases. At one end of the spectrum a Miss W of Newtown appears to have provided care for a single patient in return for domestic help. Caterham, on the other hand, one of the huge Metropolitan Asylum Board (MAB) institutions that ringed London, was described as a "very large establishment" and accommodated 13 Dorset cases. ${ }^{39}$ The variety of different establishments used appears to reflect both an attempt to match individual circumstances with available provision, and an acute shortage of beds that required extensive searches for any suitable accommodation. Pinney's report hinted as much, although the controversial conclusions, outlined later, that he drew from the visits suggest it was compiled for quite a different purpose.

The report contains many interesting remarks about the institutions visited, the staff running them, the condition of patients maintained, and the attitude of their relatives. On the whole, Pinney found all the establishments well managed and the inmates reasonably content. Pinney cannot be regarded as an impartial observer, but it should be remembered

\footnotetext{
${ }^{37}$ The RWCI files include no comparable documents from any of the other partner local authorities.

${ }^{38}$ Dorset Record Office (hereafter DorRO), A15/1/

3, Dorset County Council Mental Deficiency Act
}

Committee (hereafter Dorset MDA Com) minutes, vol. 3, 1925-1928, 29 Jan. 1927, Appendix 1, pp. 8-9. Pinney's report was written in 1926 and presented to the MDA Com in January 1927.

${ }^{39}$ Ibid, p. 8. 
Institutional Care for the Mentally Defective, 1914-1948

Table 1

Dorset cases maintained in institutions

\begin{tabular}{|c|c|c|c|c|c|c|}
\hline \multirow{2}{*}{ Institution } & \multicolumn{3}{|c|}{ Dorset cases late 1926} & \multicolumn{3}{|c|}{ Dorset cases late 1932} \\
\hline & Males & Females & Total & Males & Females & Total \\
\hline Bodvan (Carnarvon Poor Law) & - & 2 & 2 & - & 1 & 1 \\
\hline Brentry (colony) & 1 & - & 1 & - & - & $\begin{array}{l}1 \text { on } \\
\text { licence }\end{array}$ \\
\hline Bridport Poor Law & - & 9 & 9 & - & 28 & 28 \\
\hline Calderstones & 2 & - & 2 & - & - & - \\
\hline Care of farm & 1 & - & 1 & - & - & - \\
\hline Care of Miss W & - & 1 & 1 & - & - & - \\
\hline Caterham (MAB) & 7 & 6 & 13 & 5 & 2 & 7 \\
\hline Church Army Walthamstow & - & 3 & 3 & - & - & $\begin{array}{l}1 \text { on } \\
\text { licence }\end{array}$ \\
\hline Cirencester Poor Law & 1 & 2 & 3 & - & - & - \\
\hline Darenth Colony (MAB) & 3 & 5 & 8 & - & - & - \\
\hline $\begin{array}{l}\text { Devon and Exeter Home of the } \\
\text { Good Shepherd }\end{array}$ & - & 3 & 3 & - & 10 & 10 \\
\hline Fareham Poor Law & 7 & - & 7 & 5 & - & 5 \\
\hline Ford House Devonport & - & 4 & 4 & - & - & - \\
\hline Fountain Mental Hospital (MAB) & 1 & 1 & 2 & - & - & - \\
\hline Hildenborough farm colony & 1 & - & 1 & - & - & - \\
\hline Leavesden (MAB) & 2 & 2 & 4 & 1 & 3 & 4 \\
\hline Mount Tabor & - & 2 & 2 & - & 4 & 4 \\
\hline Rock Hall, Bath & - & 1 & 1 & 1 & - & 1 \\
\hline Royal Earlswood & - & 2 & 2 & 1 & 1 & 2 \\
\hline RWCI Starcross & 6 & 3 & 9 & 37 & 22 & 59 \\
\hline Sandfield (semi-private) & - & - & - & - & - & - \\
\hline Shepton Mallet Poor Law & - & 1 & 1 & - & - & - \\
\hline Shirley (semi-private) & - & 1 & 1 & - & - & - \\
\hline Stoke Park Colony & 7 & 1 & 8 & 6 & 4 & 10 \\
\hline Stourbridge Poor Law & 8 & 6 & 14 & 4 & - & 4 \\
\hline Tenterden Poor Law & - & 3 & 3 & - & 1 & 1 \\
\hline $\begin{array}{l}\text { Whittington Hall, Church of } \\
\text { England Home }\end{array}$ & - & 1 & 1 & - & 1 & 1 \\
\hline Awaiting institutional treatment & $\mathrm{n} / \mathrm{a}$ & $\mathrm{n} / \mathrm{a}$ & $\mathrm{n} / \mathrm{a}$ & 10 & 7 & 17 \\
\hline In other institutions not used in $1926^{*}$ & $\mathrm{n} / \mathrm{a}$ & $\mathrm{n} / \mathrm{a}$ & $\mathrm{n} / \mathrm{a}$ & 14 & 10 & 24 \\
\hline $\begin{array}{l}\text { Total } \\
\text { (Including on licence) }\end{array}$ & 47 & 59 & 106 & 84 & 94 & $\begin{array}{r}178 \\
(180)\end{array}$ \\
\hline
\end{tabular}

* The new institutions included the Sandlebridge Colony and the St Raphael's Colony but the largest single group were maintained in Stapleton PLI.

Sources: figures compiled from DorRO A15/1/3, Dorset MDA Com minutes, 29 Jan. 1927, Appendix 1, and RWCI collection, box 25, correspondence files, list of Dorset cases with ages at 1 Dec. 1932. 


\section{Graham Chester and Pamela Dale}

that this was the heyday of mental deficiency institutions and the negative reputation that they acquired after 1948 cannot be assumed to have applied in earlier periods. While patients suffered the same loss of civil rights on being institutionalized, the more severe criticisms that centred on overcrowding, poor staff morale leading to cases of neglect and abuse, and decaying facilities, remain to be substantiated. Many facilities were newly constructed at this period, even if they were designed to maximize economy rather than comfort.

A total of 27 Dorset patients were maintained in four MAB asylums, although there was increasing pressure from the Board of Control to return patients to the South West of England. Darenth Training Colony accommodated a total population of 2400, but only eight Dorset cases. The medical superintendent there seems to have had little confidence in his ability to train them, noting that most cases were congenital; Pinney unkindly suggested "the proof of his statement being the types of parents and relations who appeared on visiting days". ${ }^{40}$ If training opportunities were limited, however, the care offered was often exemplary. Pinney noted that two severely handicapped patients were kept alive only by "skilled nurses" in Fountain Hospital (another MAB establishment). Research was reported to be a priority for the medical superintendent of that institution but Pinney describes neither its subjects nor objectives, if indeed he knew. Leavesdon (MAB) was praised for being well managed but, while the two male patients from Dorset were thought to be "comparatively sensible and contented", it was understood that nothing could be done for the two female cases found to be "blind, deaf, immobile and helpless in every way". ${ }^{41}$

Notes accompanying later applications (from Devon as well as Dorset patients) to the RWCI tend to suggest that most of the patients in the MAB asylums had been there a long time; in fact most cases pre-dated the 1913 act and were not moved because there was no other suitable accommodation. The sheer number of beds, and the level of medical attention available, was impossible to replicate in the regions and these patients were removed only at the insistence of the Board of Control. While MAB asylums have a fairly grim reputation in the literature, with Elaine Murphy offering a particularly detailed critique of their regimes, ${ }^{42}$ contemporary accounts do not present them as destinations of last resort. Eyewitness reports from Poor Law facilities are also more complimentary than might be assumed from Board of Control concerns about the use and misuse of such accommodation. It is, however, noticeable that Dorset used such accommodation differently to other local authorities that have been studied. In Devon, the St Thomas Union workhouse had long been used as a staging post to various asylums, but this was strictly for a limited period while a bed was sought or an assessment of mental state was made. In Devon the use of Poor Law accommodation was limited until Devon County Council took over the Axminster and Crediton workhouses as specialist mental deficiency facilities after the 1929 Local Government Act, thereby copying Somerset's example. ${ }^{43}$ Although there were rumours of more than 100 certified and uncertified cases in Devon workhouses in the early 1930s, this

\footnotetext{
${ }^{40}$ Ibid, p. 8.

${ }^{41}$ While eugenic concerns tended to focus on the "feeble-minded group", the care of the most severely handicapped was often a more immediate, and expensive, problem for local authorities.
}

\footnotetext{
${ }^{42}$ Elaine Murphy, 'The Lunacy Commissioners and the East London Guardians, 1845-1867', Med. Hist., 2002, 46: 495-524, p. 521.

${ }^{43}$ There was some discussion about the temporary use of Devon workhouses during the First World War
} 


\section{Institutional Care for the Mentally Defective, 1914-1948}

problem was ignored by the statutory authority. ${ }^{44}$ There was little effort to count the number of potential patients in workhouses and no long-term plans for their accommodation were initiated. The few Poor Law cases that were actively dealt with by the statutory authority were mostly children who had grown up in care, and some cases involving destitution and homelessness. The situation in Dorset was quite different.

In Dorset adult cases were allowed to accumulate in a variety of workhouses before 1929 and these were later re-configured as specialist facilities. Dorset cases were maintained in eight different certified Poor Law institutions in 1926. Interestingly, by no means all of them were local workhouses as the list included Ford House (Devonport) and facilities at Shepton Mallet (Somerset), Cirencester (Gloucestershire), Stourbridge (Worcestershire), Tenterden (Kent), Bodvan (Carnarvon) and Fareham (Hampshire), in addition to Bridport (main Dorset facility). The Board of Control wanted this accommodation run down but in Dorset there was a determination to increase it, especially for women, and a flattering account of the different institutions appears in Pinney's report. While Shepton Mallet (a long-time specialist centre in Somerset) was described as only "satisfactory", Fareham was reported to be "admirably managed", and at Bodvan patients were "strong and healthy and kept under kind control". ${ }^{45}$ There are indications that more beds had been sought at such facilities but the impressive Stourbridge institution with "fine buildings and grounds" was reportedly oversubscribed and refusing 100 applicants per month. ${ }^{46}$ Despite its Poor Law origins, this institution was being developed to conform to the colony model and, as such, provided much sought-after accommodation.

The Board of Control had strongly advocated colonies as the ideal solution to the problem of mental deficiency and encouraged the transfer of patients to them. Pinney duly inspected the four colonies where Dorset patients were maintained but, although he reported that Stoke Park was "a well run Gloucestershire Institution", and Calderstones

but it appears that neither the County Council nor the local Guardians were keen to develop this policy. The Board of Control had identified Totnes workhouse as having suitable accommodation but the Guardians reported they had room for only their own inmates. DRO 153/5/1/1, 22 Nov. 1917, minute 113b, and 26 Feb. 1918, minute 122. Torrington workhouse had been offered to the mental deficiency committee but it was declined because of the cost of necessary adaptations. DRO 153/5/1/1, 29 Aug. 1917, minute 101. There was then very little discussion about workhouse inmates before 1929, although some parts of South Molton workhouse were used for mental deficiency cases between 1917 and 1939. The significant numbers of cases later reported to be in these institutions were possibly the responsibility of Poor Law Guardians and later the Public Assistance Committee. In one 1935 report, 104 inmates were listed in former workhouses appropriated by the council for mental deficiency work, while a further 92 individuals were recorded in three certified public assistance institutions, but the history and future of this accommodation was not discussed in any detail. Unpublished work on the Devon census for 1881 (undertaken as part of the Exminster Project) by Joseph Melling and others suggests that at least 116 "idiots" were accommodated in fourteen Devon workhouses.

${ }^{44}$ DRO $153 / 5 / 1 / 2$, A short summary of the administration of the Mental Deficiency Acts 1913-1927 in the county, in relation to institutional accommodation by John R Harper, chairman of the Mental Deficiency Committee, 18 Nov. 1935, pp. 1-3. This report listed 668 individuals under mental deficiency orders and accommodated in various institutions or maintained on licence or under guardianship in Devon and elsewhere. A further 95 workhouse inmates were certified under the 1890 Lunacy Act and needed transferring to the mental deficiency sector, and there were at least 146 individuals who were in a similar situation although currently uncertified. There were also 224 patients inappropriately accommodated in the mental hospital; the medical department knew of a further 1047 individuals at large in the community and were monitoring 361 borderline cases. This was in addition to new referrals of ineducable children expected from the education department.

${ }^{45}$ DorRO A15/1/3, Dorset MDA Com, minutes, 29 Jan. 1927, Appendix 1, pp. 8-9.

${ }^{46}$ Ibid, p. 9. 


\section{Graham Chester and Pamela Dale}

a "magnificent new County Institution", this was no guarantee that Dorset could, or would want to, access more of these beds. ${ }^{47}$ Demand for beds was rapidly outstripping supply and there appeared no hope of immediately increasing the number of Dorset cases from the 12 then maintained in different colonies. The lack of colony accommodation available to Dorset did not, however, lead to the creation of a colony in the county. While the number of Dorset cases maintained in colonies tended to increase over time, so did the number of patients in alternative forms of accommodation (Tables 1,2). There is little evidence to suggest that colonies were recognized as an ideal solution for Dorset mental deficiency cases. Instead a number of options were pursued.

Pinney himself made a series of recommendations for the MDA Committee to consider. He first noted that he had written to inform patients' next of kin of his visits and reported on their welfare. He claimed to have "received many courteous and grateful replies", although, tellingly, he recommended that three of the four specific requests made to him should be refused by the Committee. He further recommended that, "having seen these 27 institutions, in various parts of England, and talked with many of their doctors, it is very evident that strict segregation or sterilisation is necessary for the protection of our race". ${ }^{48}$

Detailed proposals to extend surveillance for mental deficiency cases and send all cases found to institutions followed. Pinney recommended that once in institutions all male patients should be sterilized and then, if possible, released, while all female defectives were to be sterilized or "kept in rigid segregation". He further argued that patients were as content in "District Unions" (presumably local workhouses with a mixed population of inmates) as they were at Royal Earlswood (the most prestigious specialist institution in England) so long as mental defectives were kept apart from other classes of pauper. While the Board of Control strongly advocated a medical model of care, associated with colony provision, Pinney thought "the magnificent buildings and large staffs of doctors, nurses and attendants are an unnecessary expense to the state". 49

Pinney documented Dorset's somewhat chaotic arrangements for placing cases in a variety of institutions in 1926. The situation was not ideal, but neither was there any enthusiasm within the statutory authority for a wholesale revision of the arrangements. While Pinney stressed the onerous burden of care and expense represented by the Dorset mental deficiency cases, and came up with unacceptable plans to reduce this through programmes of segregation and sterilization, there are other ways of reading his report. Persons concerned for the welfare of individual patients would have been encouraged by the attempt to match individual care requirements with the different regimes offered by the variety of institutions available. They might also have welcomed the information that the Dorset patients in the different institutions were well cared for and generally content. While many of the elite figures, lay officials and councillors as well as doctors, responsible for the administration of the MDAs appear to have had limited faith in the potential of people certified as mentally defective, it was hard to move from abstract discussions about the value of future prevention to supporting eugenic segregation, let alone sterilization in any individual case. Instead, local cases were visited with a clear eye to their comfort and

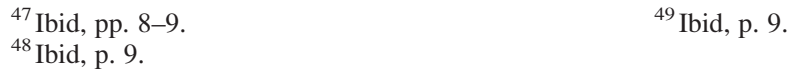


Institutional Care for the Mentally Defective, 1914-1948

Table 2

The increase in Dorset cases institutionalized in various facilities

\begin{tabular}{|c|c|c|}
\hline Institution & $\begin{array}{l}\text { Dorset cases late } 1932 \\
\text { (adapted from Table 1) }\end{array}$ & $\begin{array}{l}\text { Dorset cases, revised } \\
\text { list April } 1933\end{array}$ \\
\hline Besford Court & 3 & 3 \\
\hline Bodvan (Carnarvon Poor Law) & 1 & 1 \\
\hline Brentry (colony) & 1 & 1 \\
\hline & on licence & on licence \\
\hline Bridport (former PLI) & 28 & $\begin{array}{c}28 \\
\text { (includes } 1 \text { on licence) }\end{array}$ \\
\hline Caterham & 7 & 7 \\
\hline Church Army Walthamstow & $\begin{array}{c}1 \\
\text { on licence }\end{array}$ & $\begin{array}{c}1 \\
\text { on licence }\end{array}$ \\
\hline $\begin{array}{l}\text { Devon and Exeter Home of the } \\
\text { Good Shepherd }\end{array}$ & 10 & 10 \\
\hline Fareham Poor Law & 5 & 5 \\
\hline Girls village home (Berkshire) & 2 & 1 \\
\hline Hillside & 1 & 1 \\
\hline Home of the Holy Innocents (Exeter) & 2 & 2 \\
\hline Hortham Colony (Bristol) & - & 58 \\
\hline Leavesden & 4 & 4 \\
\hline Mount Olivier (Frensham) & 2 & 2 \\
\hline Mount Tabor & 4 & 5 \\
\hline Rock Hall, Bath & 1 & 1 \\
\hline Royal Earlswood & 2 & 2 \\
\hline RWCI Starcross & 59 & 60 \\
\hline St Raphael's Colony & 1 & 1 \\
\hline Sandlebridge & 2 & 2 \\
\hline Stapleton (former PLI) & 11 & 10 \\
\hline Stoke Park Colony & 10 & 11 \\
\hline Stourbridge Poor Law & 4 & 4 \\
\hline Tenterden Poor Law & 1 & 1 \\
\hline Whittington Hall & 1 & 1 \\
\hline Under Guardianship & $\mathrm{n} / \mathrm{a}$ & 11 \\
\hline Awaiting institutional treatment & 17 & $\begin{array}{l}\quad 7 \\
\text { (described as under } \\
\text { section } 15 \text { orders in } \\
\text { PAIs) }\end{array}$ \\
\hline Dorset cases in state institutions & $\mathrm{n} / \mathrm{a}$ & 11 \\
\hline Total (includes those on licence) & $178(180)$ & $248(251)$ \\
\hline
\end{tabular}

Sources: figures compiled from DorRO A15/1/3, Dorset MDA Com minutes, 29 Jan. 1927, Appendix 1, and RWCI collection, box 25, correspondence files, list of Dorset cases with ages at 1 Dec. 1932 and quarterly summary dated 31 Mar. 1933. 


\section{Graham Chester and Pamela Dale}

welfare, and a deep sense of personal responsibility (to the individuals concerned as well as a commitment to public service) imbued the work. In Dorset certain cases were placed under the guardianship of named officials who were expected to take a personal as well as administrative interest in their welfare. ${ }^{50}$

The ideological consensus that facilitated mental deficiency work was, as is evident from Thomson's work, extremely complex. A careful balance had to be maintained between care, control and cost. The Dorset arrangements, described by Pinney, arguably achieved this in 1926. The situation had, however, changed by 1932, and by 1933 there was a clear campaign to reduce the number of institutions used. ${ }^{51}$ The institutional population maintained by Dorset County Council had increased by almost 68 per cent, and this was in line with increases elsewhere associated with the publication of the Wood Report on Mental Deficiency in $1929 .{ }^{52}$ Furthermore, there had been significant movements between institutions, and between different types of institutions.

\section{Efforts to Rationalize Institutional Care}

Without significant accommodation of its own, Dorset is perhaps best understood as a purchaser or commissioner of services, although its independence was constrained by oversight from the Board of Control. The purchasing role created a series of relationships with different service providers that offer insights into the problematic delivery of institutional care under the Mental Deficiency Acts. Crucially, the 1930s continued to be a decade of a significant expansion as well as reconfiguration of services commissioned by Dorset. More patients were institutionalized and significant numbers of inmates were transferred (Tables 1,2). Correspondence about these patient transfers suggests that Dorset County Council did not usually instigate these moves. The transfers therefore provide little evidence of local authority dissatisfaction with existing arrangements. Instead, they highlight the pressure the Board of Control was exercising to bring local practices into conformity with central government policy that stressed the importance of having a comprehensive local mental deficiency service. It also appears that transfers were prompted by oversubscribed institutions requesting the removal of out-of-county cases (these were often channelled through the Board of Control), the Board of Control criticizing the placement of individuals or groups of patients, relatives seeking to bring patients to institutions closer to home, and occasionally funding crises. Thus, while the pattern of institutional placements in 1933 was very different from that of 1926, this was not necessarily a sign of success for the Dorset MDA Committee, nor was it easily achieved.

There were two major policy changes in Dorset as well as some underlying themes affecting mental deficiency work elsewhere. Dorset, like Devon, was being encouraged to remove patients from the MAB asylums, and, even if transfers were few, deaths gradually reduced the number of patients maintained there. There was also a tendency not to renew

\footnotetext{
${ }^{50}$ See RWCI Collection, box 25, correspondence files, letter from Hyde to C W Mayer 13 Apr. 1933, re Kathleen B.

${ }^{51}$ RWCI Collection, box 25, correspondence files, letter from J L Torr to C W Mayer, 4 Apr. 1933.

${ }^{52}$ Report of the Mental Deficiency Committee being the Joint Committee of the Board of Education and the
}

Board of Control, 1925-29 (Wood Report), London, HMSO, 1929. For discussion of this report and its findings, see Thomson, op. cit., note 1 above, pp. 60, 97, 183, 209-11, 308 . 


\section{Institutional Care for the Mentally Defective, 1914-1948}

contracts with the smallest homes once existing patients (usually singletons) died or were discharged. This development must in part have been linked to new arrangements for guardianship. The more significant institutional changes involved the former Bridport workhouse and the RWCI.

Bridport workhouse had long been used for mental deficiency cases and this role was significantly expanded after the county council took over the facility. This was entirely compatible with the Dorset strategy for mental deficiency work outlined in Pinney's 1926 report but was viewed with suspicion by the Board of Control. In order to limit the number and type of cases that could be maintained there, the Board of Control required that use of the former workhouse be first approved, and then reviewed for renewal at three-yearly intervals. ${ }^{53}$ The Board was always keen to exclude children and "high-grade" cases from Bridport and tended to increase these restrictions over time. This was despite the fact that the unique combination of care and control such institutions were thought to offer was valued by the local authority, and by other providers of institutional care who did not wish to admit difficult cases. ${ }^{54}$ In 1939 a temporary three-year extension was granted only on condition that the institution was reserved for older "medium to low grade" women. Even this limited approval was linked to Dorset's future use of the expanded RWCI, where phase two was then under construction. ${ }^{55}$

The Board of Control had long encouraged the evolving relationship between Dorset County Council and the RWCI. However, Dorset did not view the RWCI as central to its future plans, and took up relatively few beds at the institution compared with the local authorities of Devon and Plymouth. ${ }^{56}$ As a junior partner, Dorset struggled to influence the allocation of beds. Moreover, when the first major partnership agreement was negotiated in 1926, the RWCI had been clearly identified as an educational establishment and most Dorset cases were unsuited, because of age or ability, for this type of provision. ${ }^{57}$ Despite

\footnotetext{
${ }^{53}$ Dorset was not the only local authority to experience problems with their workhouse accommodation. In 1939 the Devon County Council clerk informed the RWCI that the Board of Control "were not prepared to continue the approval of South Molton and other Public Assistance Institutions indefinitely", but suggested that removing cases the Board of Control were particularly concerned about to the RWCI might help. RWCI Collection, box 25, Devon County Council correspondence, letter from clerk to C W Mayer, 23 Mar. 1939.

${ }^{54}$ For example, correspondence between $\mathrm{C} \mathrm{W}$ Mayer and Hyde re Rose T, Jan. 1934. The RWCI refused to treat the admission of Rose as urgent on the grounds that she was already institutionalized, but later more disturbing information emerged and they turned down the application despite noting that a "period of discipline in the Bridport Institution" might have improved her character. RWCI Collection, box 25, correspondence files, letter from Hyde to C W Mayer, 2 Jan. 1934, and reply 6 Jan. 1934. See further correspondence, J L Torr to C W Mayer, 10 Jan. 1934, and reply, 29 Jan. 1934. This referred to particulars sent in Nov. 1933.
}

\footnotetext{
${ }^{55}$ These points were outlined in a letter from the
} Board of Control to the clerk of Dorset County Council, later copied to the RWCI, dated 24 Apr. 1939. RWCI Collection, box 25 .

${ }^{56}$ Dorset's initial involvement was fairly modest, with an outline agreement to secure 50 of the planned 530 new beds. RWCI Collection, box 30, DCC (colony), C W Mayer to J L Torr, draft agreement with revisions, 2 Oct. 1933, pp. 1-4. The county boroughs of Exeter and Plymouth are distinct from the administrative county of Devon. All three (plus Somerset, Dorset and, in a limited way, Cornwall) were partners of the RWCI, although Devon and Plymouth took more beds than the others and consequently were more involved in determining the future of the institution.

${ }^{57}$ The RWCI admitted 2503 patients between 1 April 1914 and 31 March 1939. It is noteworthy that 2167 of these patients were classed as "feeble-minded" and only 346 of the admissions involved adults aged 21 or older. 


\section{Graham Chester and Pamela Dale}

pressure from the Board of Control and Devon County Council for a relaxation of the admission criteria, this was a gradual process, and priority continued to be given to the young and trainable. Dorset was left in a difficult position. In a review of cases following the 1929 Local Government Act, Dorset needed provision for 540 ascertained cases, of whom 188 were then maintained in certified institutions, with a further 100 cases due to be transferred from the Poor Law authorities. ${ }^{58}$

The partnership agreement with the RWCI was negotiated on this basis. Yet the county council must have been concerned that Dorset provided institutional care for only six educable children (most already at the RWCI), and had 152 institutionalized adults to place (55 of whom were under notice of removal). ${ }^{59}$ To compound these problems, extensions at Starcross were delayed and interim measures had to be found. The Board of Control appears have encouraged a new partnership with Hortham Colony, Bristol (see Table 2). At the outset, Dorset's involvement with Hortham seemed to follow the pattern of other successful collaborations but soon became a serious financial liability. Dorset had already discovered that colonies were ideal if other authorities were prepared to bear the capital expense of building them. Colonies built for large numbers of patients took time to fill with local cases and sometimes a financially embarrassed colony-provider was prepared to lease beds cheaply to Dorset. This was far more cost-effective than self-building but was not without problems; not least the difficulty that the colonies soon filled up and new out-ofcounty cases were refused. Dorset seems to have hit problems with this from time to time, as closure to new cases was often accompanied by pressure to discharge ones admitted earlier. During a particular crisis, Dorset signed a partnership agreement to assist with the expansion of the RWCI, but delays in completing the scheme encouraged a new deal with the Hortham Colony. This proved ill-advised as the Hortham superintendent had a contract allowing him to charge Dorset for empty beds while operating very strict admission criteria that excluded most patients on the council waiting list. Patients had to be moved en masse from other, even cheaper, institutions to reduce the wasted expenditure. ${ }^{60}$

Long-term partners, like the RWCI, were annoyed by this episode, reminding Dorset that their low costs were due to careful economy and a policy of using the labour of "highgrade" patients to subsidize the rest. ${ }^{61}$ The RWCI was also dismayed that the Board of Control was using competition between different institutions, and associated patient transfers, to force changes to their admission criteria. In particular, patients were admitted to, and discharged from, the state hospitals in a way that encouraged the development of regional secure units, although the institutions themselves had not planned this. ${ }^{62}$ The secure units, with inevitable long-stay populations, upset developing relationships between institutional and community care: the emphasis on security detracted from the care aspects of the work, thereby undermining public and, crucially, parental support. ${ }^{63}$ The integrated

\footnotetext{
${ }^{58}$ RWCI Collection, box 25, correspondence files, extract of report of [Dorset] Mental Deficiency Committee, 20 May 1931, sent to C W Mayer with covering letter from J L Torr, 22 May 1931.

${ }^{59}$ Ibid.

${ }^{60}$ RWCI Collection, box 25, correspondence files, letter from Hyde to C W Mayer, 31 Jan. 1933.

${ }^{61}$ RWCI Collection, box 25, correspondence files, letter from C W Mayer to Hyde, 2 Feb. 1933.
}

\footnotetext{
${ }^{62} \mathrm{See}$, for example, correspondence between the Board of Control and Dorset County Council re Joyce G, 11 June and 17 July 1934, RWCI Collection, box 25. The Board wanted Joyce presented for admission to the RWCI, or alternatively Hortham, and would consider an application to Rampton only if she proved unmanageable in a certified institution.

${ }^{63} \mathrm{C}$ W Mayer addressed the benefits of institutional care and its key role in supporting community care in
} 


\section{Institutional Care for the Mentally Defective, 1914-1948}

penal-welfare provision outlined by commentators like David Garland was thus highly problematic for individual institutions while being entirely compatible with overall service development. $^{64}$

\section{Conclusion}

Evidence from the South West of England confirms that institutions were vital to the implementation of the Mental Deficiency Acts. This conclusion tends to confirm the thesis that they provided a distinct locus of care also supporting arrangements for extra-institutional care. Yet, within this institutional provision there was greater diversity than many commentators have allowed for. The failure fully to develop the colony solution allowed pre-existing institutions to exert disproportionate influence over the future delivery of services. Here it is worth noting the contribution of the original five English voluntary idiot institutions (including the RWCI) and the MAB asylums. At the same time, the limited supply of specialist beds required local authorities to turn to other providers of institutional care. Thus the Poor Law, and its gradual fragmentation, was intimately connected with the development of mental deficiency services although the full implications of this, institutional and otherwise, have not been fully explored to date. The provision of workhouse care under the MDAs has been neglected as a research topic, although the ideological connections between workhouses, prisons and different types of asylums inspired Garland's work and led to a very pessimistic assessment of mental deficiency work. ${ }^{65}$ In this respect it is interesting to note that Pinney found least optimism amongst medical staff at the largest MAB asylums.

If anything, the diversity of institutional provision serving the South West of England suggests a continuum of care and control options. Literature that presents community care as more benign than the institutional sector does, however, miss the point that the two were intimately connected. In presenting community care as an alternative to institutional care there is also a tendency to use a static model of both. This paper has found evidence of significant developments in both sectors and an evolving relationship between the two. This is not to imply accrued benefits to service users but should be taken into account in any assessment of care either sought or offered.

The ongoing involvement of a variety of statutory and voluntary sector organizations in mental deficiency work in the South West of England highlights the importance of the mixed economy of care; with cooperation and competition both in evidence. These findings lend support to the work of Thomson, Jackson, Wright, Digby and Bartlett, ${ }^{66}$ but also suggest the value of case studies that foreground the provision of institutional care after 1914. Three distinct models for the provision of institutional care are suggested. While these were clearly not the only options available, there are indications that variations on these arrangements were common to many English local authorities, with the definite

his speech to the annual meeting of the Dorset Voluntary Association, 30 Mar. 1936, although his scripted remarks make no reference to the ongoing negotiations with Dorset County Council. RWCI

Collection, box 31 .

\footnotetext{
${ }^{64}$ Garland, op. cit., note 3 above.

${ }^{65}$ Ibid., pp. 241-2.

${ }^{66}$ See references in note 1 above.
} 


\section{Graham Chester and Pamela Dale}

exception of those accessing the MAB system. The model of care and control pioneered in Somerset was probably the most successful, in the sense that it met stated local aspirations while achieving conformity with Board of Control requirements, although this assessment should be tempered by the acknowledged shortfall in available accommodation and the financial and organizational constraints that explained this. In Somerset it does appear that the mix of institutional and community-based services which the statutory authority could and did utilize provided opportunities for a phased expansion of services. This reduced the severity of the short-term crises that often paralysed long-term planning in Devon and Dorset.

In Somerset the coordination of effort between the statutory and voluntary sectors seems to have been particularly important. In Devon and Dorset there were close personal links as well as organizational ties between the two sectors, although crucially no dominant figure equivalent to Mrs Cooke-Hurle of Somerset emerges from the records of either county. ${ }^{67}$ We are also able to confirm the importance of the mixed economy of care, and suggest that the range of services identified were viewed differently by the various actors involved, and their opinions were subject to revision over time. It has not been possible to detail the response of service-users and their families, although this remains a goal for future research. It is, however, noteworthy that most of the filed RWCI correspondence relates to active requests for institutional care; from prospective patients, parents and others.

We do not wish to offer an overly optimistic assessment of institutional care for the mentally defective. The loss of liberty was unacceptable to some contemporary as well as most modern commentators, while the care provided was often limited, and regard for personal circumstances was frequently subordinated to the management of a large and heterogeneous population of "defectives". Yet the care provided was less homogenous than some critical accounts suggest and this diversity allowed for competing interpretations of what represented the best model of care. Over time it seems that the diversity of institutional care available came to be regarded as a welcome resource for "purchasers" of care, because it allowed individuals to be placed in institutions that best met their personal needs. However, mental deficiency campaigners continued to bemoan the lack of policy coherence that had allowed the situation to arise. It is certainly the case that the many and varied institutions in use across the South West of England in the 1930s could be presented as a comprehensive mental deficiency service, but it was not the one envisaged by supporters of the original campaign for the 1913 Mental Deficiency Act.

\footnotetext{
${ }^{67}$ The closest equivalent is Lt-Col F B Nixon who served as Chairman of the Dorset MDA Committee and acted as the Dorset representative on the Joint Committee of the RWCI, but he was far less prominent in decision making at the RWCI and his role with other voluntary organizations is unclear. Also in Dorset,
}

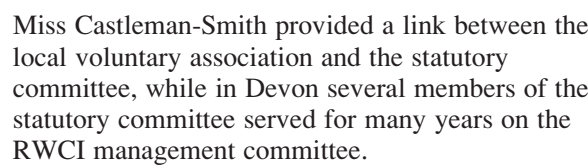

